\title{
Impact of Income on Perceived Stress, Coping, and Family Functioning in Indian Females with Pseudoseizures
}

\author{
Richa Mehta $^{1}$ Anuj Mittal ${ }^{1}$ Dweep Singh ${ }^{2}$ Chirag Patel ${ }^{3}$ \\ ${ }^{1}$ Department of Psychiatry, Deen Dayal Upadhyay Hospital, \\ Address for correspondence Richa Mehta, BA, MA, MPhil, \\ New Delhi, India \\ 2Department of Clinical Psychology, Amity University, Noida, \\ Department of Psychiatry, Deen Dayal Upadhyay Hospital, \\ Uttar Pradesh, India \\ ${ }^{3}$ Department of Psychiatry, Shree Agarsen International Hospital, \\ New Delhi, India \\ Int J of Ep:2020;6:43-49
}

\begin{abstract}
Background Pseudoseizures are paroxysmal alterations in behavior that resemble epileptic seizures but are without any organic cause. Stress, coping, and family functioning are contributing factors in the development and maintenance of pseudoseizures. Literature has found patients with pseudoseizures to belong to lower economic strata; however, no study has directly looked at the impact of income on the core contributing and maintaining factors of pseudoseizures.

Aim This article studies the impact of income on perceived stress, coping, and family functioning in females with pseudoseizures.

Materials and Methods Ninety-one females with pseudoseizures were recruited from the psychiatry department of a tertiary care hospital in New Delhi, India. Each participant completed the Perceived Stress Scale, Ways of Coping Questionnaire, and McMasters Family Assessment Device-General Functioning Scale. Other sociodemographic variables including per capita family monthly income, level of education, area of residence, and employment status were also recorded.

Results Planful Problem Solving and Positive Reappraisal were positively associated with per capita income, while escape-avoidance coping was found to be negatively associated with per capita income. Results also showed a statistically significant negative relationship between perceived stress scores, family functioning, and per capita family income, with income having the highest contribution to family functioning in females with dissociative convulsions.

Keywords

Conclusion Income was a significant contributor to perceived stress, coping processes, and family functioning. Therefore, high levels of perceived stress, greater familial dysfunction, and maladaptive coping had negative impacts on the outcome of female patients with pseudoseizures belonging to lower income group.
\end{abstract}

\section{Introduction}

Dissociation is defined as "a disruption in the usually integrated functions of consciousness, memory, identity, or perception of the environment."1 Pseudoseizures are a specific

DOI https://doi.org/ $10.1055 / \mathrm{s}-0040-1715766$ ISSN 2213-6320. form of dissociation which involve "involuntary experiential and behavioral responses to internal or external triggers that superficially resemble epileptic seizures but which are not associated with the abnormal electrical activity associated with epileptic seizures," ${ }^{2}$ therefore, pseudoseizures are 
paroxysmal alterations in behavior that resemble epileptic seizures but are without any organic cause. ${ }^{3}$

Pseudoseizures are a state of altered awareness which acts as an avoidance response, protecting the individual from stressful events, and function as a coping strategy. ${ }^{4}$ Historically, pseudoseizures were known as hysterical seizures and were regarded as a manifestation of an emotional disturbance. ${ }^{5}$ Dissociation would appear to be an essential feature of pseudoseizures, which in turn might be viewed as a form of nonverbal communication of emotional distress, ${ }^{6}$ possibly representing a wish to escape from a difficult or unpleasant situation. ${ }^{7}$ International Classification of Diseases, 10th Revision (ICD-10) categorizes pseudoseizures as dissociative disorders ${ }^{8}$ and the ICD, 11th Revision, lists such attacks as "dissociative neurological symptom disorder, with nonepileptic seizures."

Perceived stress reflects the interaction between an individual and their environment which they appraise as stressful. ${ }^{10}$ The same situation may be appraised differently by different individuals due to their psychosocial correlates and thus have a different impact on each. With respect to women, the multiple role requirements of childbearing and child rearing, running the family home, caring for sick relatives, and earning an income have found to lead to considerable stress. ${ }^{11}$ In extension of the concept of stress as a cause of dissociation, the coping process that an individual employs in dealing with stressors and problems aids in the understanding of dissociative disorders. Coping is the cognitive and behavioral efforts made to master, tolerate, or reduce external and internal demands and conflicts among them. ${ }^{12}$ The seizure-like behaviors have been conceived of as resulting from a maladaptive coping approach to stressful situations that are perceived as unbearable. ${ }^{13}$ Patients with pseudoseizures have also been observed to have difficulties in family functioning, especially in the domains of communication, affective involvement, and general functioning. ${ }^{14}$ On the other hand, pseudoseizures have also been conceptualized as serving a function of garnering attention for the patient within the family, especially for those individuals who feel a lack of concern from their families. ${ }^{15}$ Thus, dysfunctional family patterns, ${ }^{16}$ perceived stress, and coping strategies employed are all contributing factors in the development and maintenance of pseudoseizures.

Socioeconomic status is a complex concept that is assessed indirectly using a variety of different measures such as income, occupational status, and education. ${ }^{17}$ Literature has consistently identified a higher prevalence of females with dissociative convulsions as belonging to a middle to low income group, ${ }^{16,18-22}$ where low income was found to be associated with several lifetime mental disorders and suicide attempts and a reduction in income overtime was associated with increased risk for incident mental disorders. ${ }^{22}$

A review of available literature reveals that little is known about the impact of income on perceived stress, coping strategies, and family functioning in females with dissociative seizures. While several studies have identified patients with pseudoseizures as hailing from a low socioeconomic stratum, none have directly studied the contribution of income to the causes and consequences of the patients' psychopathology. The present study was an attempt to explore relationship and contribution of income on perceived stress, coping strategies, and family functioning in females with dissociative convulsions.

\section{Aim}

The aim of this article was to assess the contribution of income on perceived stress, coping strategies employed, and family functioning of females with pseudoseizures.

\section{Materials and Methods}

\section{Participant Selection}

The participants were 91 female patients diagnosed with dissociative convulsions, according to the criteria laid down by ICD-10, ${ }^{8}$ recruited consecutively from the psychiatry outpatient department (OPD). Participants were referred from neurology and general medicine units to the psychiatry OPD of a tertiary care hospital in India. The diagnosis of dissociative convulsions was established clinically by a team of psychiatrists and clinical psychologist.

\section{Inclusion Criteria}

1. Age: 18 to 45 years.

2. Dissociative convulsions (according to ICD-10 criteria).

3. Sex: Female.

\section{Exclusion Criteria}

1. A concurrent clinical diagnosis of psychosis, organic brain syndrome, drug dependence, or mental retardation.

2. History of major medical disorders such as diabetes mellitus, major cardiac problems, chronic renal failure, chronic liver disease, autoimmune diseases, and comorbid seizure disorder.

\section{Procedure}

After the procedure was carefully explained to the participant, a written informed consent for participation in the study was obtained from them. A detailed psychiatric history and mental status examination was conducted following which each participant completed the Cohen's Perceived Stress Scale, ${ }^{10}$ Folkman and Lazarus' Ways of Coping Questionnaire, ${ }^{23}$ McMasters Family Assessment Device (FAD)-General Functioning Scale, ${ }^{24}$ and semistructured sociodemographic performa. All questionnaires were translated and back translated by bilingual experts. Per capita monthly income was defined as the family's total monthly income divided by the number of partakers and income was divided into quartiles based on the distribution of the sample. This method of dividing household income into quartiles has been used in several epidemiological studies to ensure adequate power in each of the categories. ${ }^{25}$ 


\section{Tools}

\section{Cohen's Perceived Stress Scale ${ }^{10}$}

Cohen's Perceived Stress Scale is a 10-item scale designed to measure the degree to which one perceives aspects of life as uncontrollable, unpredictable, and overloading. Participants were asked to respond to each question on a 5-point Likert scale ranging from 0 to 4 , indicating how often they have felt or thought a certain way within the past month. Scores range from 0 to 40, with higher composite scores indicative of greater perceived stress.

\section{Folkman and Lazarus' Ways of Coping Questionnaire ${ }^{23}$}

Ways of Coping Questionnaire is a 66-item questionnaire designed to assess coping processes used in a particular stressful encounter (and not coping styles or traits). It measures eight ways of coping, namely confrontative coping, distancing, self-controlling, seeking social support, accepting responsibility, escape-avoidance, Planful Problem Solving, and Positive Reappraisal. Participants were asked to respond to each question on a 4-point Likert scale ranging from 0 to 3 , indicating the extent to which it was used.

\section{McMaster's Family Assessment Device-General Functioning Scale ${ }^{24}$}

The 12-item subscale of General Functioning was utilized from The McMaster FAD. It has been validated as a single index measure to assess family functioning. The measure includes statements about family communication and support, on a 4-point Likert scale. The average of the individual item scores is then calculated, with scores greater than or equal to 2.0 indicating family dysfunction.

\section{Semistructured Sociodemographic Performa}

Was used to record the following sociodemographic information of the participants:

- Monthly per capita income: The sum of net monthly salaries and other income (pensions, dividends, interests, or rents) contributed by each household member was divided by the number of family members (regardless of age) to generate a per capita monthly income. Per capita income was treated both as a continuous and categorical (quartiles and deciles) variable and was arbitrarily subdivided in four equal categories of INR $\geq 5,000,5,001$ to $10,000,10,001$ to 15,000 , and 15,001 to 20,000 .

- Education: Participants' own educational level was subdivided in five categories according to whether participants were illiterate or had completed primary education (1-5 years), metric (6-9 years), secondary education (1012 years), or graduation (more than 12 years).

- Employment status: Participants' current employment status was recorded. The two subcategories were employed (paid occupation) and unemployed (work without remuneration).

- Area of residence: Participants' permanent area of residence was recorded. The two subcategories were urban areas (cities, towns, conurbations, or suburbs) and rural areas (villages and hamlets).

\section{Analysis}

The data were entered on MS Excel and analyzed by SPSS version 23 using appropriate descriptive (mean, standard deviation [SD], range, and frequency) and interpretative statistics (bivariate correlation, linear regression, $t$-test). All $p$-values less than 0.05 were considered to be statistically significant. Results of inferential analysis indicate that the sample of the study was normally distributed.

\section{Results}

The study included 91 subjects diagnosed with pseudoseizures. - Table 1 shows the relevant demographic profile of the study sample. Descriptive analysis of the sample revealed that the female were between the ages of 18 and 45 years (mean $=30.34, \mathrm{SD}=8.82$ ), with the majority $(51.6 \%)$ being under 30 years of age. Most participants were illiterate (28.6\%) or educated unto primary school (28.6\%), majority (73.6\%) were unemployed, and primarily belonged to rural parts of northern India (54.9\%). The mean per capita monthly income was INR $4,734( \pm 2,895)$, with the minimum income being INR 750 and the maximum being INR 20,000 and where a large percentage (71.4\%) had a monthly per capita income less than INR 5,000.

To understand the magnitude and direction of correlation relationships, a bivariate correlational analysis of per capita income with perceived stress, coping strategies, and family functioning in females with pseudoseizures was performed. - Table 2 states that three kinds of coping strategies were statistically significant with the patients' per capita income. Both Planful Problem Solving and Positive Reappraisal were positively associated with per capita income $(p<0.01)$, while escape-avoidance coping was found to be negatively associated with per capita income $(p<0.05)$. Results showed a statistically significant negative relationship between perceived stress scores and per capita income $(p<0.01)$ as well as between family functioning and per capita income $(p<0.05)$ (where higher scores on family functioning scale indicate higher dysfunction in the family).

To address the potential differential contribution of income on perceived stress, coping strategies, and family functioning in females with pseudoseizures, a linear regression analysis was conducted. Findings shown in - Table 3 indicate that the largest contribution was found on Positive Reappraisal (37.7\%) significant at $p<0.001$, followed by Perceived Stress (31.2\%) significant at $p<0.01$ and family functioning (26.6\%) significant at $p<0.01$.

To assess the difference between per capita income categories (> INR 5,000 and < INR 5,000) with respect to perceived stress, coping strategies, and family functioning in females with pseudoseizures, a Student's $t$-test was applied, as depicted in - Table 4 . Results were indicative of a statistically significant difference between the two income groups on perceived stress, escape-avoidance coping, Planful Problem Solving, Positive Reappraisal, and family functioning $(p<0.01)$. Findings also showed a highly significant difference between the two income groups on Positive Reappraisal $(p<0.01)$ as a coping strategy. 
Table 1 Sociodemographic profile $(N=91)$

\begin{tabular}{|c|c|c|c|c|c|}
\hline & $n$ & Percentage (\%) & Mean & SD & Range \\
\hline Per capita monthly income (INR) & & & $4,734.87$ & $2,895.78$ & 16,500 \\
\hline$<5,000$ & 65 & 71.4 & & & \\
\hline $5,001-10,000$ & 22 & 24.2 & & & \\
\hline $10,001-15,000$ & 3 & 3.3 & & & \\
\hline $15,001-20,000$ & 1 & 1.1 & & & \\
\hline Age $(y)$ & & & 30.34 & 8.82 & 36 \\
\hline$>30$ & 47 & 51.6 & & & \\
\hline$<30$ & 44 & 48.3 & & & \\
\hline \multicolumn{6}{|l|}{ Education (y) } \\
\hline Illiterate & 26 & 28.6 & & & \\
\hline Primary & 26 & 28.6 & & & \\
\hline Metric & 22 & 24.2 & & & \\
\hline Senior secondary & 11 & 12.1 & & & \\
\hline Graduation & 6 & 6.6 & & & \\
\hline \multicolumn{6}{|l|}{ Employment status } \\
\hline Employed & 24 & 26.4 & & & \\
\hline Unemployed & 67 & 73.6 & & & \\
\hline \multicolumn{6}{|l|}{ Area of residence } \\
\hline Urban & 41 & 45.1 & & & \\
\hline Rural & 50 & 54.9 & & & \\
\hline \multicolumn{6}{|l|}{ Marital status } \\
\hline Married & 47 & 51.6 & & & \\
\hline Unmarried & 36 & 39.6 & & & \\
\hline Widow & 3 & 3.3 & & & \\
\hline Divorced & 5 & 5.5 & & & \\
\hline Live-in relationship & 0 & 0 & & & \\
\hline \multicolumn{6}{|l|}{ Family structure } \\
\hline Nuclear & 56 & 61.5 & & & \\
\hline Joint & 19 & 20.9 & & & \\
\hline Extended & 16 & 17.6 & & & \\
\hline
\end{tabular}

Abbreviation: SD, standard deviation.

An additional analysis revealed that income and education have a strong association ( $r=0.450 ; p>0.001)$, where higher income was seen to be associated with higher level of education. Income was seen to contribute to $20.2 \%$ to education, which is a significant contribution $(p>0.001)$.

\section{Discussion}

The aim of this study was to assess the relationship with and contribution of income to perceived stress, coping strategies employed, and family functioning of females with pseudoseizures.

An analysis of the findings revealed that the "typical" participant in the current sample would be a 30-year-old unemployed, less educated female hailing from a rural background with an average monthly per capita income of less than INR 5,000 . These findings are in broad agreement with other studies that have found a higher prevalence of dissociative convulsions among females belonging to a middle- to low-income group with less educational qualifications ${ }^{16,18-20,22}$ and hailing from rural areas. ${ }^{26}$ 
With respect to the relationship and contribution of income, it may be inferred from the current findings that income had a significant impact on perceived stress (31.2\%), family functioning (26.6\%), and coping strategies (80.4\%). An analysis of data showed that participants with per capita income less than INR 5,000 reported higher levels of perceived stress, greater familial dysfunction, and were more likely to engage in maladaptive coping like escape-avoidant, when compared with higher income categories. High perceived stress, ${ }^{27,28}$ poor family functioning, ${ }^{16,29}$ and greater use of escape-avoidant coping $27,28,30$ have all been found to be contributing factors in the development and maintenance of pseudoseizures. The present study added to the existing body of literature by specifying the amount of money in Indian rupees which corresponded to an increased likelihood of developing dissociative convulsions within a vulnerable population. It was found that participants with a per capita income below INR 5,000, were significantly more likely to develop dissociative convulsions; however, these findings cannot be generalized beyond the current sample.

The association of low income with increased psychopathology in the sample may be explained by the observation that living with less income maybe detrimental to one's

Table 2 Correlation ( $r$ ) of income with perceived stress, coping processes, and family functioning $(N=91)$

\begin{tabular}{|c|c|}
\hline Measures & Income \\
\hline \multicolumn{2}{|l|}{ Coping processes } \\
\hline Confrontative & 0.139 \\
\hline Distancing & -0.008 \\
\hline Self-controlling & 0.065 \\
\hline Seeking social support & 0.164 \\
\hline Accepting responsibility & -0.035 \\
\hline Escape-avoidance & $-0.258^{\mathrm{a}}$ \\
\hline Planful Problem Solving & $0.257^{\mathrm{a}}$ \\
\hline Positive Reappraisal & $0.377^{\mathrm{b}}$ \\
\hline Perceived stress & $-0.312^{b}$ \\
\hline Family functioning & $-0.266^{a}$ \\
\hline
\end{tabular}

asignificant at the 0.05 level.

bsignificant at the 0.01 level. physical and mental health, as financial hardships create a context of stress in which stressors continue to multiply and eventually contribute to mental health problems. ${ }^{31}$ Here, individuals continually face a lack of opportunity, reduced availability and accessibility to resources, and a greater likelihood of experiencing difficult events. ${ }^{32}$ Several other mechanisms such as overcrowding, hunger, violence, social networks, and a decreased capacity to acquire health care may increase the perceived stress in lower income groups and thus perpetuate mental health problems. ${ }^{33}$ The resultant distress may manifest in a variety of presentations, where literature pertaining to the Indian context, has found a high presentation of physical symptoms without any identifiable organic causes. ${ }^{32}$ Literature also suggests that greater distress related to negative life events may be associated with increased use of maladaptive and emotion-focused coping in patients with dissociative convulsions. ${ }^{28}$ As a consequence, psychopathology in women is shown to have an impact on family functioning due to the woman's role in running the domestic activities of the household. ${ }^{34}$

An additional analysis revealed that income and education have a strong positive association, which is consistent with previous literature. ${ }^{35,36}$ Income was also seen to contribute significantly to education (20.2\%). An implication of these findings is that low education may be a potentially preventable risk factor of developing pseudoseizures, as education may influence aspirations, self-image, and permit greater choices in life decisions. ${ }^{37}$

\section{Conclusion}

High levels of perceived stress, greater familial dysfunction, and maladaptive coping had negative impacts on the outcome of female patients with pseudoseizures belonging to lower income group. Here, an increase in income level above INR 5,000 (US \$73), was seen to correspond with lower levels of stress and family dysfunctionality and greater use of adaptive coping strategies such as Planful Problem Solving and Positive Reappraisal. It may be inferred from the current findings that within the basic per capita income category of $>$ INR 5,000 , a majority of females with dissociative convulsions

Table 3 Linear regression of income on perceived stress, significant coping processes, and family functioning $(N=91)$

\begin{tabular}{|c|c|c|c|c|c|}
\hline & $R^{2}$ & Standardized $\beta$ & $\begin{array}{l}\text { Standard error } \\
\text { of } \beta\end{array}$ & t-Ratio & Significance \\
\hline Positive Reappraisal & 0.377 & 289.73 & 75.47 & 3.83 & $0.001^{c}$ \\
\hline Perceived stress & -0.312 & -137.63 & 44.39 & -3.10 & $0.003^{b}$ \\
\hline Family functioning $^{d}$ & -0.266 & $-1,149.53$ & 440.85 & -2.60 & $0.01^{b}$ \\
\hline Planful Problem Solving & 0.257 & 179.59 & 71.72 & 2.50 & $0.01^{b}$ \\
\hline Escape-avoidance & -0.17 & -124.87 & 74.09 & -1.70 & 0.09 \\
\hline
\end{tabular}

dHigher scores on family functioning scale indicate higher dysfunction. 
Table 4 Difference between income categories $(N=91)$

\begin{tabular}{|c|c|c|c|c|c|}
\hline Measures & Group & $n$ & Mean (SD) & $t$ & $p$-Value \\
\hline \multirow[t]{2}{*}{ Perceived stress } & $>5,000$ & 65 & $28.78(6.53)$ & \multirow[t]{2}{*}{-2.173} & \multirow[t]{2}{*}{$0.03^{b}$} \\
\hline & $<5,000$ & 26 & $25.54(6.1)$ & & \\
\hline \multicolumn{6}{|l|}{ Coping processes } \\
\hline \multirow[t]{2}{*}{ Confrontative } & $>5,000$ & 65 & $10.17(3.28)$ & \multirow[t]{2}{*}{1.12} & \multirow[t]{2}{*}{0.26} \\
\hline & $<5,000$ & 26 & $10.96(2.28)$ & & \\
\hline \multirow[t]{2}{*}{ Distancing } & $>5,000$ & 65 & $6.05(3.24)$ & \multirow[t]{2}{*}{0.03} & \multirow[t]{2}{*}{0.97} \\
\hline & $<5,000$ & 26 & $6.08(4.34)$ & & \\
\hline \multirow[t]{2}{*}{ Self-controlling } & $>5,000$ & 65 & $6.35(3.30)$ & \multirow[t]{2}{*}{1.05} & \multirow[t]{2}{*}{0.29} \\
\hline & $<5,000$ & 26 & $7.23(4.23)$ & & \\
\hline \multirow[t]{2}{*}{ Seeking social support } & $>5,000$ & 65 & $9.34(4.25)$ & \multirow[t]{2}{*}{1.610} & \multirow[t]{2}{*}{0.11} \\
\hline & $<5,000$ & 26 & $10.96(4.57)$ & & \\
\hline \multirow[t]{2}{*}{ Accepting responsibility } & $>5,000$ & 65 & $6.02(3.46)$ & \multirow[t]{2}{*}{-0.51} & \multirow[t]{2}{*}{0.61} \\
\hline & $<5,000$ & 26 & $5.62(3.16)$ & & \\
\hline \multirow[t]{2}{*}{ Escape-avoidance } & $>5,000$ & 65 & $15.52(4.28)$ & \multirow[t]{2}{*}{-2.06} & \multirow[t]{2}{*}{$0.04^{b}$} \\
\hline & $<5,000$ & 26 & $13.58(3.42)$ & & \\
\hline \multirow[t]{2}{*}{ Planful Problem Solving } & $>5,000$ & 65 & $5.38(3.98)$ & \multirow[t]{2}{*}{2.12} & \multirow[t]{2}{*}{$0.03^{a}$} \\
\hline & $<5,000$ & 26 & $7.38(4.24)$ & & \\
\hline \multirow[t]{2}{*}{ Positive Reappraisal } & $>5,000$ & 65 & $3.78(3.07)$ & \multirow[t]{2}{*}{4.19} & \multirow[t]{2}{*}{$0.001^{b}$} \\
\hline & $<5,000$ & 26 & $7.15(4.29)$ & & \\
\hline \multirow[t]{2}{*}{ Family functioning } & $>5,000$ & 65 & $2.72(0.64)$ & \multirow[t]{2}{*}{-1.90} & \multirow[t]{2}{*}{$0.05^{a}$} \\
\hline & $<5,000$ & 26 & 2.43. (0.70) & & \\
\hline
\end{tabular}

Abbreviation: SD, standard deviation.

${ }^{a} p<0.01$.

${ }^{\mathrm{b}} \mathrm{p}<0.001$.

Table 5 Difference between Income groups on sociodemographic profile $(N=91)$

\begin{tabular}{|l|l|l|l|l|l|l|l|l|l|}
\hline \multirow{2}{*}{$\begin{array}{l}\text { Income } \\
\text { categories }\end{array}$} & \multicolumn{4}{|c|}{ Education $(f)$} & \multicolumn{3}{c|}{ Employment status $(f)$} & \multicolumn{2}{c|}{ Area of residence $(f)$} \\
\cline { 2 - 11 } & Illiterate & Primary & Metric & $\begin{array}{l}\text { Senior } \\
\text { secondary }\end{array}$ & Graduation & Employed & Unemployed & Urban & Rural \\
\hline$<5,000$ & 22 & 11 & 20 & 10 & 2 & 13 & 52 & 17 & 48 \\
\hline $5,001-10,000$ & 4 & 14 & 2 & 0 & 2 & 9 & 13 & 21 & 1 \\
\hline $10,001-15,000$ & 0 & 1 & 0 & 1 & 1 & 1 & 2 & 2 & 1 \\
\hline $15,001-20,000$ & 0 & 0 & 0 & 0 & 1 & 1 & 0 & 1 & 0 \\
\hline
\end{tabular}

were unemployed (- Table 5) in our sample. These findings could have implications for prevention of dissociative psychopathology especially in low-income countries, suggesting that grassroots intervention should be undertaken to ensure education and employment for females. Since the level of education is related with employment ${ }^{11}$ and eventually with per capita income, ${ }^{38}$ it may be inferred that an increase in the level of education may act as a protective factor in dissociative convulsions, as it will eventually increase income, reduce stress, and provide the individual with opportunities to learn more adaptive coping processes. Indeed, another comparative study with higher income group of nonworking female patients is needed to validate these findings.
However, the direction of the association of income with perceived stress, coping strategies, and family functioning, in females with pseudoseizures remains unclear, here, as with any cross-sectional study design, the findings of the current study cannot be used to provide a definite indication of causal direction, what is clear is that it is not a unidimensional oneway relationship but rather an interactive and complexly dynamic one. Another limitation of the current study is that the majority of participants recruited for the study had an income below INR 5,000, as the data was collected from a tertiary care government hospital offering free of cost treatment to patients. This considerably limits the generalization of our findings. Future studies can explore the same questions in clients from diverse socioeconomic backgrounds. 


\section{Conflict of Interest}

None declared.

\section{References}

1 Agarwal V, Sitholey P, Srivastava C. Clinical practice guidelines for the management of dissociative disorders in children and adolescents. Indian J Psychiatry 2019;61(8, Suppl 2) :247-253

2 Reuber M, Brown RJ. Understanding psychogenic nonepileptic seizures-phenomenology, semiology and the integrative cognitive model. Seizure 2017;44:199-205

3 Bhatia MS. Pseudoseizures. Indian Pediatr 2004;41(7):673-679

4 Mehta R, Mittal A, Singh DC, Patel C. Perceived stress and coping strategies in females with psychogenic non-epileptic seizures in a tertiary care hospital, New Delhi. Delhi Psychiatr J 2019;22(1):82-88

5 Lesser RP. Psychogenic seizures. Psychosomatics 1986;27(12): 823-829

6 Kuyk J, Van Dyck R, Spinhoven P. The case for a dissociative interpretation of pseudoepileptic seizures. J Nerv Ment Dis 1996;184(8):468-474

7 Minter RE. Can emotions precipitate seizures-a review of the question. J Fam Pract 1979;8(1):55-59

8 World Health Organization. International Statistical Classification of Diseases and Related Health Problems, 10th revision;2016.Availableat: http://apps.who.int/classifications/ icd10/browse/2016/en. Accessed July 9, 2018

9 World Health Organization. International Statistical Classification of Diseases and Related Health Problems, 11th Revision; 2018. Available at: https://icd.who.int/browse11/ l-m/en. Accessed April 2019

10 Cohen S, Kamarck T, Mermelstein R. A global measure of perceived stress. J Health Soc Behav 1983;24(4):385-396

11 Patel V, Araya R, de Lima M, Ludermir A, Todd C. Women, poverty and common mental disorders in four restructuring societies. Soc Sci Med 1999;49(11):1461-1471

12 Folkman S, Lazarus RS. An analysis of coping in a middle-aged community sample. J Health Soc Behav 1980;21(3):219-239

13 Lafrance WC, Bjørnæs H, Designing treatment plans based on etiology of PNES. In: Gates and Rowan's Nonepiletic Seizures. New York: Cambridge University Press; 2010:283-299

14 Krawetz P, Fleisher W, Pillay N, Staley D, Arnett J, Maher J. Family functioning in subjects with pseudoseizures and epilepsy. J Nerv Ment Dis 2001;189(1):38-43

15 Moore PM, Baker GA, McDade G, Chadwick D, Brown S. Epilepsy, pseudoseizures and perceived family characteristics: a controlled study. Epilepsy Res 1994;18(1):75-83

16 Deka K, Chaudhury PK, Bora K, Kalita P. A study of clinical correlates and socio-demographic profile in conversion disorder. Indian J Psychiatry 2007;49(3):205-207

17 Araya R, Lewis G, Rojas G, Fritsch R. Education and income: which is more important for mental health? J Epidemiol Community Health 2003;57(7):501-505

18 Irfan N, Badar A. Top ten stressors in the hysterical subjects of Peshawar. J Ayub Med Coll Abbottabad 2002;14(4):38-41

19 Uğuz S, Toros F. Sociodemographic and clinical characteristics of patients with conversion disorder [in Turkish]. Turk Psikiyatr Derg 2003;14(1):51-58
20 Khan MN, Ahmad S, Arshad N, Ullah N, Maqsood N. Anxiety and depression symptoms in patients with conversion disorder. J Coll Physicians Surg Pak 2005;15:489-492

21 Reddy LS, Patil NM, Nayak RB, Chate SS, Ansari S. Psychological dissection of patients having dissociative disorder: a cross-sectional study. Indian J Psychol Med 2018;40(1):41-46

22 Tabassum K, Farooq S. Sociodemographic features, affective symptoms and family functioning in hospitalized patients with dissociative disorder (convulsion type). J Pak Med Assoc 2007;57(1):23-26

23 Folkman S, Lazarus RS, Manual for the Ways of Coping Questionnaire: Research Edition. California: Consulting Psychologists Press; 1988

24 Epstein NB, Baldwin LM, Bishop DS. The McMaster Family Assessment Device. Fam J (Alex Va) 1983;9(2):171-180

25 Sareen J, Afifi TO, McMillan KA, Asmundson GJ. Relationship between household income and mental disorders: findings from a population-based longitudinal study. Arch Gen Psychiatry 2011;68(4):419-427

26 Al Jiboori SD. Symptoms frequencies and stressors in the hysterical subjects. QMJ 2008;4(5):11-20

27 Frances PL, Baker GA, Appleton PL. Stress and avoidance in pseudoseizures: testing the assumptions. Epilepsy Res 1999;34(2-3):241-249

28 Testa SM, Krauss GL, Lesser RP, Brandt J. Stressful life event appraisal and coping in patients with psychogenic seizures and those with epilepsy. Seizure 2012;21(4):282-287

29 Aamir S, Jahangir SF, Farooq S. Family functioning among depressive and dissociative (conversion) patients. J Coll Physicians Surg Pak 2009;19(5):300-303

30 Myers L, Fleming M, Lancman M, Perrine K, Lancman M. Stress coping strategies in patients with psychogenic non-epileptic seizures and how they relate to trauma symptoms, alexithymia, anger and mood. Seizure 2013;22(8):634-639

31 Wadsworth ME, Raviv T, Reinhard C, Wolff B, Santiago CD, Einhorn L. An indirect effects model of the association between poverty and child functioning: the role of children's poverty-related stress. J Loss Trauma 2008;13(3):156-185

32 Kuruvilla A, Jacob KS. Poverty, social stress \& mental health. Indian J Med Res 2007;126(4):273-278

33 Insel TR. Assessing the economic costs of serious mental illness. Am J Psychiatry 2008;165(6):663-665

34 Malik SC. Women and mental health. Indian J Psychiatry 1993;35(1):3-10

35 Kishore J, Reddaiah VP, Kapoor V, Gill JS. Characteristics of mental morbidity in a rural primary health centre of Haryana. Indian J Psychiatry 1996;38(3):137-142

36 Mumford DB, Saeed K, Ahmad I, Latif S, Mubbashar MH. Stress and psychiatric disorder in rural Punjab. A community survey. Br J Psychiatry 1997; 170:473-478

37 Brown GW, Harris TO, Bifulco A, Long-term effects of early loss of parent. In: Depression in Young People: Developmental and Clinical Perspectives. New York: Guilford Press; 1986:251-296

38 Rutter M, Madge N, A Review of Research. London: Heinemann; 1976 